\title{
ON THE VALIDITY OF THE POLAROGRAPHIC DETERMINATION OF STABILITY CONSTANTS OF METAL IONS IN THE CASE OF ADSORBABLE ELECTROACTIVE SPECIES
}

\author{
M. SLUYTERS-REHBACH and J. H. SLUYTERS \\ Laboratory of Analytical Chemistry, State University, Utrecht (The Netherlands) \\ (Received 20th November 1971; in revised form 13th March 1972)
}

\section{INTRODUCTION}

D.c. and a.c. polarography are widely applied in the study of complex formation, especially of metal ions which are reversibly reduced at the dropping mercury electrode(DME). Analysis of the shift in half-wave or peak potential as a function of the ligand concentration enables the various stability constants to be determined, e.g. according to the method of Deford and Hume ${ }^{1}$. Useful information on the details of the polarographic method can be found in the monograph by $\mathrm{Crow}^{2}$.

The advantage of the polarographic over other methods, e.g. equilibrium potential measurements, is that it is sufficient to have only the Ox-component of the redox couple, i.e. the metal ion of interest, present. Recently, however, Bond and Hef$\operatorname{ter}^{3}$ have thrown some doubt on the validity of the method. Their reasoning was that, if the complexing ligand is adsorbed at the surface of the DME, the reacting metal ion would meet a larger concentration of ligand on its way through the double layer and that thus, owing to what is called "additional complexation", the half-wave potential would shift to a more negative value than corresponded to the ligand concentration in the bulk of the solution. In this way apparently larger stability constants would be reported than from equilibrium potential measurements at an amalgam electrode.

As mentioned by Bond and Hefter, arguments supporting the idea of additional complexation can be derived from studies by Kalvoda et $a .^{4}$ and Anson and Barclay ${ }^{5}$. The latter proved that metal complexes may be adsorbed at the mercury-solution solution interface owing to a surface reaction with ligand already adsorbed.

In their paper Bond and Hefter reported experiments on lead-halide systems which show that for bromide and iodide the polarographic results differ from the potentiometric results. These differences especially led us to examine the problem in more detail, because we felt that possible adsorption of the electroactive species, which naturally occurs in both the polarographic and potentiometric experiments, should affect both methods in the same way, if the reactions are fast. Since it can be expected that adsorption does not affect the equilibrium method, this should mean that the polarographic method also is not invalidated. This has been considered on the basis of a comparison of the two methods.

\section{(i) Equilibrium measurements}

Consider an amalgam electrode containing the metal $\mathrm{R}$ in contact with a solu- 
tion of the corresponding metal ion $0^{n+}$ containing a complexing agent $\mathrm{L}$. The ionic strength is kept constant by means of a non-complexing indifferent electrolyte so that activity coefficients may be ignored. For each species the thermodynamic potential is defined as:

$$
\mu_{\mathrm{i}}=\mu_{\mathrm{i}}^{0}+R T \ln c_{\mathrm{i}}^{*}
$$

where $\mu_{\mathrm{i}}^{0}$ is the standard thermodynamic potential and $c_{\mathrm{i}}^{*}$ the bulk concentration. The equilibrium potential $E_{\text {eq }}$ of the system follows from the well-known relation

or

$$
\mu_{\mathrm{o}}-n F E_{\mathrm{eq}}=\mu_{\mathrm{R}}
$$

$$
\begin{aligned}
E_{\mathrm{eq}} & =\left(\mu_{\mathrm{O}}^{0}-\mu_{\mathrm{R}}^{0}\right) / n F+(R T / n F) \ln \left(c_{\mathrm{O}}^{*} / c_{\mathrm{R}}^{*}\right) \\
& =E^{0}+(R T / n F) \ln \left(c_{\mathrm{O}}^{*} / c_{\mathrm{R}}^{*}\right)
\end{aligned}
$$

The stability constant $\beta_{p}^{*}$ for the complex $\mathrm{OL}_{p}$ in the bulk of the solution is also related to the standard thermodynamic potentials by:

$$
R T \ln \beta_{p}^{*}=R T \ln \left[c_{\mathrm{O} \mathrm{L}_{\mathrm{p}}}^{*} / c_{\mathrm{O}}^{*}\left(c_{\mathrm{L}}^{*}\right)^{p}\right]=\mu_{\mathrm{O}}^{0}+p \mu_{\mathrm{L}}^{0}-\mu_{\mathrm{OL}}^{0}
$$

When several complexes exist simultaneously, it is convenient to introduce the analytical concentration $c_{O T}^{*}$ of the dissolved metal ion, which is given by:

$$
\begin{aligned}
c_{\mathrm{OT}}^{*} & =c_{\mathrm{O}}^{*}+c_{\mathrm{OL}}^{*}+c_{\mathrm{OL}}^{*}+\ldots c_{\mathrm{OL}}^{*} \\
& =c_{\mathrm{O}}^{*}\left[1+\beta_{1}^{*} c_{\mathrm{L}}^{*}+\beta_{2}^{*}\left(c_{\mathrm{L}}^{*}\right)^{2}+\ldots \beta_{p}^{*}\left(c_{\mathrm{L}}^{*}\right)^{p}\right] \\
& =c_{\mathrm{O}}^{*} / r_{\mathrm{O}}
\end{aligned}
$$

With this, the Nernst eqn. (3) can be written quite operationally as:

$$
E_{\mathrm{eq}}=E^{0}+(R T / n F) \ln r_{\mathrm{O}}+(R T / n F) \ln \left(c_{\mathrm{OT}}^{*} / c_{\mathrm{R}}^{*}\right)
$$

This equation shows how $r_{O}$ can be determined. Analysis of $r_{\mathrm{O}}$ as a function of $c_{\mathrm{L}}^{*}$, following Deford and Hume ${ }^{1,2}$, gives the various stability constants $\beta_{p}^{*}$.

When $L$ is adsorbed in the double layer, its concentration $c_{L}$ at the surface will be different from the concentration $c_{\mathrm{L}}^{*}$ in the solution. Moreover anion-induced adsorption (or "additional complexation") of $\mathrm{O}$ or any complex $\mathrm{OL}_{p}$ may occur. The influence of this on the foregoing must be examined. As the whole system is in equilibrium, the thermodynamic potentials of all species are constant irrespective of the place in the system. This means that an increase in concentration of a species i somewhere in the double layer is accounted for by stating that the standard thermodynamic potential at the surface, $\left(\mu_{\mathrm{i}}^{0}\right)^{\mathrm{a}}$, is different from that in the bulk:

or

$$
\mu_{i}=\mu_{\mathrm{i}}^{0}+R T \ln c_{\mathrm{i}}^{*}=\left(\mu_{\mathrm{i}}^{0}\right)^{\mathrm{a}}+R T \ln c_{\mathrm{i}}
$$

$$
\left(\mu_{\mathrm{i}}^{0}\right)^{\mathrm{a}}-\mu_{\mathrm{i}}^{0}=\Delta \mu_{\mathrm{i}}^{0}=R T \ln \left(c_{\mathrm{i}}^{*} / c_{\mathrm{i}}\right)
$$

where $c_{\mathrm{i}}$ is the concentration of $\mathrm{i}$ in the adsorbed layer. Consequently we have for the complex equilibrium in the double layer

$$
\begin{aligned}
R T \ln \beta_{p} & =R T \ln \left(c_{\mathrm{OL}_{p}} / c_{\mathrm{O}}\left(c_{\mathrm{L}}\right)^{p}\right)=\left(\mu_{\mathrm{O}}^{0}\right)^{\mathrm{a}}+p\left(\mu_{\mathrm{L}}^{0}\right)^{\mathrm{a}}-\left(\mu_{\mathrm{OL}_{p}}^{0}\right)^{\mathrm{a}} \\
& =R T \ln \beta_{p}^{*}+\Delta \mu_{\mathrm{O}}^{0}+p \Delta \mu_{\mathrm{L}}^{0}-\Delta \mu_{\mathrm{OL}_{\mathrm{p}}}^{0}
\end{aligned}
$$

In fact, every $\Delta \mu_{\mathrm{i}}^{\mathrm{O}}$ consists of a possible chemical contribution and an electrical contri- 
bution, equal to $z_{\mathrm{i}} F \phi$, if there is a potential difference $\phi$ between the adsorption plane and the bulk of the solution. This is, however, not essential for our treatment.

Comparing eqns. (4) and (8), it follows that the stability constant $\beta_{p}$ at the electrode surface can differ from the stability constant $\beta_{p}^{*}$ in the bulk, if the summation of terms in $\mu_{\mathrm{i}}^{0}$ and $\left(\mu_{\mathrm{i}}^{0}\right)^{\mathrm{a}}$ differs. It may be noted that merely the adsorption of $\mathrm{L}$ is not a sufficient condition for the occurrence of adsorption of $\mathrm{O}$ or $\mathrm{OL}_{p}$, since eqn. (7b) is valid for every species. For the same reason an increase in $\mathcal{c}_{\mathrm{L}}$ at the surface does not cause precipitation of a salt $\mathrm{OL}_{n}$ from its unsaturated solution because the solubility product at the surface differs from that in the solution.

Since we are dealing with systems in equilibrium, the Nernst eqn. (3) still relates the electrode potential to the bulk concentrations of $\mathrm{O}$ and $\mathrm{R}$. With a view to the next section, it is useful to consider the relation between potential and interfacial concentrations, which follows immediately from eqns. (3) and (7):

$$
\begin{aligned}
E_{\text {eq }} & \left.=\left[\left(\mu_{\mathrm{O}}^{0}\right)^{\mathrm{a}}-\left(\mu_{\mathrm{R}}^{0}\right)^{\mathrm{a}}\right)\right] / n F+(R T / n F) \ln \left(c_{\mathrm{O}} / c_{\mathrm{R}}\right) \\
& =E^{0}+\left[\Delta \mu_{\mathrm{O}}^{0}-\Delta \mu_{\mathrm{R}}^{0}\right] / n F+(R T / n F) \ln \left(c_{\mathrm{O}} / c_{\mathrm{R}}\right)
\end{aligned}
$$

Equation (9) may be seen as a special form of the Nernst equation.

\section{(ii) Polarographic measurements}

In this section we consider a DME in contact with the same solution as above. Before the onset of the polarographic wave, the concentrations of $O$ and its complexes will be uniform up to the adsorbed layer and the concentrations in the adsorbed layer will be related to the bulk concentrations according to eqn. (7b). When a reduction current passes the interface, the concentrations of al complexes of $\mathrm{O}$ in both the adsorbed layer and outside it in the so-called diffusion layer, will decrease. It is, however, reasonable to assume that analogously to eqn. (7b) there is a relation:

$$
\Delta \mu_{\mathrm{i}}^{0}=R T \ln \left(\bar{c}_{\mathrm{i}} / c_{\mathrm{i}}\right)
$$

in which $c_{\mathrm{i}}$ is the concentration in the adsorbed layer and $\bar{c}_{\mathrm{i}}$ the concentration just outside the adsorbed layer. Equation (10) is based on the assumption that the adsorption equilibrium is sufficiently mobile, so that the concentration in the adsorbed layer conforms to the concentration just outside it, as if it were an equilibrium situation.

For a reversible electrode reaction the Nernst equation relates the electrode potential to the concentrations adjacent to the electrode surface. This means that analogously to eqn. (9) we have,

$$
E=E^{0}+\left(\Delta \mu_{\mathrm{O}}^{0}-\Delta \mu_{\mathrm{R}}^{0}\right) / n F+(R T / n F) \ln \left(c_{\mathrm{O}} / \mathcal{C}_{\mathrm{R}}\right)
$$

or, with eqn. (10),

$$
E=E^{0}+(R T / n F) \ln \left(\bar{c}_{\mathrm{O}} / \bar{c}_{\mathrm{R}}\right)
$$

Equation (12) is identical to the usual starting equation for the derivation of the expression for the half-wave potential. One principle of this derivation is that the current is maintained by the fluxes of all complex species, i.e.

$$
i=-n F\left(D_{\mathrm{R}} / \delta_{\mathrm{R}}\right) \bar{c}_{\mathrm{R}}=n F\left(D_{\mathrm{Om}} / \delta_{\mathrm{Om}}\right)\left(\bar{c}_{\mathrm{OT}}-c_{\mathrm{O} T}^{*}\right)=n F\left(D_{\mathrm{Om}} / \delta_{\mathrm{Om}}\right) \bar{c}_{\mathrm{OT}}-i_{\mathrm{d}}
$$

in which $D_{\mathrm{Om}}$ is the mean diffusion coefficient ${ }^{8}$ and $\delta_{\mathrm{i}}$ is the thickness of the diffusion layer, for a DME equal to $\delta_{\mathrm{i}}=\left(3 \pi t D_{\mathrm{i}} / 7\right)^{\frac{1}{2}}$. 
The other principle is that the equilibria between the various complexes are sufficiently mobile, and that the ligand is present in excess, so that we can write

$$
\bar{c}_{\mathrm{O}} / \bar{c}_{\mathrm{OT}}=c_{\mathrm{O}}^{*} / c_{\mathrm{OT}}^{*}=r_{\mathrm{O}}
$$

With these premises, the expression for the half-wave potential is easily derived from eqns. (12) (14) as:

$$
E_{\frac{1}{2}}=E^{0}+(R T / n F) \ln r_{\mathrm{O}}+(R T / n F) \ln \left(D_{\mathrm{R}} / D_{\mathrm{Om}}\right)^{\frac{1}{2}}
$$

\section{DISCUSSION}

The result of our considerations is that for a reversible electrode reaction, adsorption of the electroactive species affects neither the equilibrium potential, nor the half-wave potential. The essential point in our treatment is the condition that all adsorption phenomena, just as the reactions between the complexes, and the charge transfer reaction, proceed infinitely fast. Thus equations, valid under equilibrium circumstances, may still be applied, but with appropriate concentrations in accordance with the laws of diffusion. In this way thermodynamic equations also may be used for the non-equilibrium case.

The question remains: how to explain the difference observed by Bond and Hefter between polarographic stability constants and constants determined otherwise for $\mathrm{Pb}(\mathrm{II})$ with bromide and iodide? Our theory suggests that it is not correct to ascribe this to ligand adsorption or even adsorption of the electroactive species. Moreover, if this were a correct explanation, it is not clear why the phenomenon is not observed in chloride, as it is well-known that $\mathrm{Pb}$ (II) is rather strongly adsorbed from chloride solutions ${ }^{6,7}$.

We would like to emphasize that it is not our intention to question the correctness of the experimental results of Bond and Hefter. We only postulate that their qualitative explanation is probably not correct. Assuming their results are correct, an interesting consequence may be inferred. Imagine an experiment in which a polarogram is made of a dropping lead amalgam electrode in a $\mathrm{Pb}$ (II) solution. Let a reversible shape be observed. This polarogram has two characteristic points: firstly, the potential at zero current, which must be equal to the equilibrium potential; secondly the half-wave potential. If, on addition of iodide or bromide, the half-wave potential shifts more cathodically than the equilibrium potential, the polarogram necessarily loses its reversible shape. It would be interesting to check whether this occurs and we intend to do some experimental work in this direction in the near future.

\section{ACKNOWLEDGEMENT}

The authors thank Dr. A. M. Bond for a stimulating correspondence and Dr. B. G. Dekker and Drs. A. W. M. Verkroost for valuable discussions.

\section{SUMMARY}

The idea that anion-induced adsorption of the electroactive species might interfere with the determination of stability constants via shifts in the half-wave po- 
tential is critically examined. It is shown that this adsorption occurs only if the standard thermodynamic potential at the electrode-solution interface differs from that in the solution. The final conclusion is that the position of the reversible halfwave potential is not influenced by the adsorption of the electroactive species if the reactions between the complexes, and all adsorption phenomena, proceed infinitely fast.

\section{REFERENCES}

1 D. D. Deford and D. N. Hume, J. Amer. Chem. Soc., 73 (1951) 5321.

2 D. R. Crow, Polarography of Metal Complexes, Academic Press, London-New York, 1969

3 A. M. Bond and G. Hefter, J. Electroanal. Chem., 31 (1971) 477.

4 R. Kalvoda, W. Astine and M. Heyrovský, Anal. Chim. Acta, 50 (1970) 93.

5 F. C. Anson and D. J. Barclay, Anal. Chem., 40 (1968) 1971.

6 D. J. Barclay and F. C. Anson, J. Electroanal. Chem., 28 (1970) 71.

7 B. Timmer, M. Sluyters-Rehbach and J. H. Sluyters, J. Electroanal. Chem., 15 (1967) 343; 19 (1968) 73.

8 J. Heyrovský and J. Kůta, Principles of Polarography, Academic Press, London-New York, 1966, p. 155.

J. Electroanal. Chem., 39 (1972) 